\title{
Orofaciodigital syndrome type 13
}

INSERM

\section{Source}

INSERM. (1999). Orphanet: an online rare disease and orphan drug data base.

Orofaciodigital syndrome type 13. ORPHA:141330

Orofaciodigital syndrome type 13 is a rare subtype of orofaciodigital syndrome, with sporadic occurrence, characterized by cardiac (mitral and tricuspid valve dysplasia) and neuropsychiatric manifestations (epilepsy, depression), in addition to oral, facial and digital malformations (lingual hamartomas, cleft lip, brachydactyly, clinodactyly, syndactyly of hands and feet). Leukoaraiosis, on brain MRI examination, is also associated. 